\title{
Cost-Consequence Analysis of Nitisinone for Treatment of Tyrosinemia Type I
}

\author{
Mariève Simoncelli, Johanne Samson, Jean-François Bussières, Jacques Lacroix, Marc Dorais, \\ Renaldo Battista, and Sylvie Perreault
}

\begin{abstract}
Background: Tyrosinemia type I is a rare but severe genetic metabolic disorder. Nitisinone combined with a diet low in tyrosine and phenylalanine became first-line therapy in 1994 .

Objectives: To estimate the direct medical costs of health care services related to the treatment of tyrosinemia type I, taking into consideration the real-life efficacy of nitisinone.
\end{abstract}

Methods: A cost-consequence analysis was performed for all children with a confirmed diagnosis of tyrosinemia type I who were treated in Quebec between January 1, 1984, and January 1, 2009. The costs of care were compared for 3 consecutive historical groups: no nitisinone (1984 to 1994), late intervention with nitisinone (first dose received between 1994 and 1997), and early intervention with nitisinone (first dose received between 1997 and 2008). Data were derived from patient charts, hospital databases, and the Régie de l'assurance maladie du Québec and MED-ÉCHO administrative databases. Costs were reported in 2008 Canadian dollars.

Results: Nitisinone treatment was associated with significant reductions in the number and duration of hospital admissions, the number of admissions to a pediatric intensive care unit, and the number of liver transplants. The cost of hospitalization per person-year was significantly lower in the 2 groups treated with nitisinone: $\$ 673$ and $\$ 5590$ for the early-intervention and late-intervention groups, respectively, as compared to $\$ 12980$ for the no-nitisinone group $(p<0.001)$. Hospital costs per person-year for liver transplant were $\$ 3198$ for the late-intervention group and $\$ 5044$ for the no-nitisinone group: there were no transplants in the early-intervention group. The cost of nitisinone per person-year was $\$ 51493$ for the early-intervention group and $\$ 64895$ for the lateintervention group.

Conclusions: Nitisinone treatment significantly improved the outcomes of patients with tyrosinemia type I, while decreasing utilization of health care resources, liver transplants, and associated costs.

Keywords: cost-consequence analysis, nitisinone, NTBC [2-(2-nitro-4trifluoromethyl-benzoyl)-1,3-cyclohexanedione], tyrosinemia, hereditary tyrosinemia type I, health technology assessment, metabolic disorder, rare diseases, genetic disease, pharmacotherapy

\section{Can J Hosp Pharm. 2015;68(3):210-17}

\section{RÉSUMÉ}

Contexte : La tyrosinémie de type I est un trouble génétique du métabolisme rare, mais grave. La prise de nitisinone en association à un régime pauvre en tyrosine et en phénylalanine est devenue le traitement de première intention en 1994.

Objectifs : Offrir une estimation des coûts médicaux directs des services de santé liés au traitement de la tyrosinémie de type I, tout en tenant compte de l'efficacité réelle de la nitisinone.

Méthodes : Une analyse coûts-conséquences a été réalisée pour chaque enfant ayant reçu un diagnostic de tyrosinémie de type I et ayant été traité au Québec entre le $1^{\text {er }}$ janvier 1984 et le $1^{\text {er }}$ janvier 2009. Les coûts des soins ont été comparés entre trois groupes historiques se suivant dans le temps : sans nitisinone (de 1984 à 1994), traitement tardifà la nitisinone (première dose reçue entre 1994 et 1997) et traitement précoce à la nitisinone (première dose reçue entre 1997 et 2008). Les données ont été obtenues à partir de dossiers médicaux de patients, de bases de données d'hôpitaux, de la base de données administrative de la Régie de l'assurance maladie du Québec et de la banque de données ministérielles MED-ÉCHO. Les coûts sont indiqués en dollars canadiens de 2008.

Résultats : L'on a associé le traitement par nitisinone à d'importantes réductions : du nombre d'hospitalisations et de la durée des séjours à l'hôpital, du nombre d'admissions à l'unité de soins intensifs pédiatrique et du nombre de greffes hépatiques. Les coûts d'hospitalisation (par personne-année) étaient beaucoup plus faibles dans les deux groupes traités par nitisinone : $673 \$$ et 5590 \$ respectivement pour le groupe de traitement précoce et le groupe de traitement tardif, contre 12980 \$ pour le groupe sans traitement par nitisinone $(p<0,001)$. Les coûts d'hospitalisation (par personne-année) pour les greffes hépatiques étaient de 3198 \$ pour le groupe de traitement tardif et de 5044 \$ pour le groupe sans traitement par nitisinone; le groupe de traitement précoce n'a fait l'objet d'aucune greffe hépatique. Les coûts du traitement par nitisinone (par personne-année) étaient de 51493 \$ pour le groupe de traitement précoce et de $64895 \$$ pour le groupe de traitement tardif.

Conclusions : Le traitement par nitisinone améliore grandement les résultats thérapeutiques des patients souffrant de tyrosinémie de type I et réduit également le recours aux ressources en santé et à la greffe hépatique, diminuant ainsi les coûts associés.

Mots clés : analyse coûts-conséquences, nitisinone, NTBC [2-(2-nitro4-trifluorométhyl-benzoyl)-1,3-cyclohexanedione], tyrosinémie, tyrosinémie héréditaire de type I, évaluation des technologies de la santé, trouble métabolique, maladies rares, maladie génétique, pharmacothérapie 


\section{INTRODUCTION}

$\mathrm{H}_{\mathrm{h}}$ ereditary tyrosinemia type I (HT1), formerly known as hepatorenal tyrosinemia, is an autosomal recessive disorder of amino acid metabolism. ${ }^{1}$ It is characterized by a deficiency of fumarylacetoacetate hydrolase, the enzyme responsible for the last step in the breakdown of tyrosine. ${ }^{2,3}$ Accordingly, metabolites such as succinylacetone accumulate in the blood and urine, exerting toxic effects that result in liver and kidney failure if left untreated. ${ }^{3}$ The province of Quebec has the highest incidence of HT1, at 1 per 16667 live births overall and 1 per 1846 in the Saguenay-Lac-Saint-Jean region alone, ${ }^{3}$ as compared to a worldwide average of 1 per 100000 to $120000 .^{2}$ Quebec has had universal screening of newborns for inborn errors of metabolism, including HT1, since $1970 .^{4}$

HT1 of early (acute) or late (generally chronic) onset is lethal if left untreated. ${ }^{5,6}$ Failure to thrive is common. Acute liver manifestations may include ascites, jaundice, and gastrointestinal bleeding, which can progress to cirrhosis, liver failure, hepatocellular carcinoma, or hepatic encephalopathy.,3 Renal manifestations commonly include hypophosphatemic rickets, although other complications may arise, such as Fanconi syndrome, glomerulosclerosis, and renal insufficiency. ${ }^{2}$ Acute porphyria-like neurologic crises, with $10 \%$ mortality, $^{7}$ are characterized by extreme pain, hypertonia, self-mutilation, gastrointestinal symptoms, and (occasionally) progressive paralysis leading to respiratory insufficiency. ${ }^{2,3}$

Until the 1980s, the only available therapeutic option was a diet low in tyrosine and phenylalanine. Although this diet controlled acute symptoms and postponed renal damage, there was no major effect on prognosis. ${ }^{1,8}$ With the advent of liver transplant as a treatment option, survival increased, and hepatic and neurologic symptoms resolved. Nonetheless, a mortality rate of $10 \%-15 \%$ is still reported after liver transplants. ${ }^{2}$ With the availability of nitisinone [2-(2-nitro-4-trifluoromethyl-benzoyl)1,3-cyclohexanedione or NTBC], liver transplant is no longer considered, unless hepatocellular cancer is suspected or the clinical response is not good enough to overcome pre-existing liver damage (10\% of cases). NTBC treatment has also virtually eliminated the acute complications of HT1. ${ }^{9}$

NTBC is a potent inhibitor of 4-hydroxyphenylpyruvate dioxygenase, blocking the second step in tyrosine degradation and preventing formation of toxic metabolites. ${ }^{6,10}$ In the United States, this drug has been on the market since 2002. In Canada, it is available through Health Canada's Special Access Programme for nonmarketed drugs for compassionate use and became available through this avenue before licensing in the United States. In Quebec, NTBC is financed by the Quebec Ministry of Health and Social Services (Ministère de la Santé et des Services sociaux) as a province-wide program and is made available through a mother-child teaching hospital and a group of clinicians, including physicians, pharmacists, and nurses. NTBC combined with a low-tyrosine, low-phenylalanine diet became first-line therapy in Quebec in 1994. ${ }^{6,11}$ However, because of small sample sizes, therapeutic agents for rare diseases are not readily amenable to standard development on the basis of clinical trial-based evidence. Cohort studies and registries therefore assume critical importance.

Cost-consequence analyses are used to compare interventions by presenting all components of incremental costs (e.g., hospital admissions and additional health care services) and all positive and negative consequences of the interventions (e.g., health outcomes, adverse effects) without aggregation of results. Similar to formal comparative effectiveness research, the costconsequence analysis is more likely to be approachable, readily understood, and then applied by health care decision-makers. It is the first step in any economic assessment such as a costeffectiveness study or cost-utility analysis. ${ }^{12}$

To date, no pharmacoeconomic assessment of NTBC has been undertaken. "Orphan drugs" like NTBC are often associated with substantial costs. This study aimed to evaluate the direct costs of health care related to HT1 in Quebec, including NTBC and its clinical consequences.

\section{METHODS}

A cost-consequence analysis was conducted from the perspective of the Quebec health care system, using data collected retrospectively from a cohort of HT1 patients who had been followed prospectively. All children with a diagnosis of HT1 confirmed by neonatal genetic screening who were treated in Quebec between January 1, 1984, and January 1, 2009, were included. Patient follow-up centres were Centre hospitalier universitaire (CHU) Sainte-Justine (Montréal), Complexe hospitalier de la Sagamie (Chicoutimi), Centre hospitalier universitaire du Québec, Centre hospitalier de l'Université de Montréal, and the Montreal Children's Hospital.

The study was approved by the CHU Sainte-Justine Research Ethics Board and the provincial access to information commission (Commission d'accès à l'information du Québec).

The date of cohort entry was defined as birth +15 days, to ensure that results of genetic screening were available. The intervention of interest was administration of NTBC. Patients were followed until death or January 1, 2009, whichever occurred first. Three historical groups were compared: patients treated between 1984 and 1994, when the only available treatments were diet and "curative" liver transplant (no-NTBC group); patients who received the first dose of NTBC between 1994 and 1997, with NTBC being introduced at least 4 weeks after birth (lateintervention group); and patients who received the first dose of NTBC between 1997 and 2008, with NTBC being introduced within 4 weeks after birth (early-intervention group). The 3 groups were designated as described by Larochelle and others, ${ }^{9}$ except that children born from February 1, 2004, to 
January 1, 2009, were also included in the early-intervention group. In that earlier study, the clinical data were obtained in the context of a compassionate use program, and the authors reported incontestable benefits for patients' health.

\section{Data Sources}

Data were collected from administrative databases of the Quebec health care system. The MED-ÉCHO database for acute care hospital admissions (starting in 1987) was used to obtain date of admission, length of stay, primary diagnosis, and up to 15 secondary diagnoses, The Quebec health care insurance plan (the Régie de l'Assurance Maladie du Québec [RAMQ]) covers all Quebec residents for the costs of physician visits, hospital admissions, and procedures, as well as prescription drugs for residents not insured by private drug plans. ${ }^{13}$ The beneficiary database lists age, sex, and date of death, if applicable. The medical services claims database records billing for all inpatient and ambulatory services (medical acts) delivered by physicians. Diagnostic codes in MED-ÉCHO are classified according to the International Classification of Diseases, 9th revision (ICD-9; before April 2006) ${ }^{14}$ or 10th revision (ICD-10; starting in April 2006). ${ }^{15}$ Surgical procedures are classified according to the Canadian Classification of Diagnostic, Therapeutic, and Surgical Procedures. ${ }^{16}$ The pharmaceutical services database provides data on prescriptions delivered in community pharmacies for patients insured by the RAMQ drug plan, such as fill date, medication, dose, quantity, and duration of therapy. These data were available as of 1997 . Validation studies conducted on the pharmaceutical and medical claims databases have confirmed their validity in the context of other diseases. ${ }^{17,18}$

Data on prescriptions for NTBC were available from records of the hospital pharmacy of CHU Sainte-Justine, a tertiary care pediatric hospital and the only dispensary for this drug; these data were available as of 1997. Data on prescriptions for patients admitted for liver transplant were available from treatment protocols before 2000 and from the pharmacy electronic database starting in 2000. Use of blood products was retrieved from the CHU Sainte-Justine blood bank database and hospital records.

Clinical outcomes of interest were suggested by the Québec NTBC Study Group, a group of clinicians who have been following the Quebec cohort of children with HT1. A review of patient charts provided clinical data not otherwise available in the administrative databases, such as the occurrence of neurologic crises and additional data specific to liver transplants.

\section{Estimates of Direct Health Care Costs}

Only direct hospital costs and drug costs attributable to HT1 were considered. A sub-analysis of costs related to liver transplant was conducted, including hospital admissions, medical services, therapeutic agents, and blood products.

Hospital costs were categorized as relating to general hospital admissions, liver transplants, and admissions to the pediatric intensive care unit (PICU). Hospital and PICU expenditures were calculated using standard CHU Sainte-Justine per diem costs for the year in question, multiplied by the number of days in hospital.

For an accurate representation of resource utilization, other costs had to be factored in, such as consultations with allied health care professionals (e.g., audiologists or genetic counsellors in hospitals or outpatient clinics). Utilization of these services was available from MED-ÉCHO, and their costs were estimated from the hospital's annual financial reports.

Costs related to medical visits, surgeries, and procedures were assessed from the RAMQ medical services database, using the Quebec fee schedules for specialists ${ }^{19}$ and general practitioners ${ }^{20}$ for the year in question. Expenditures for visits to the emergency department were evaluated from data provided by the Quebec hospital association (Association québécoise d'établissements de santé et de services sociaux). ${ }^{21}$ Pharmaceutical costs, including pharmacist fees, were obtained directly from the RAMQ pharmaceutical services database.

Costs are reported in 2008 Canadian dollars, equivalent to about US $\$ 0.94$ at then-current exchange rates. ${ }^{22}$ Drugs and nonphysician costs were discounted at $3 \%$ annually to 2008 ; the annual discount for all other costs was $5 \% .{ }^{23}$

\section{Statistical Analysis}

Cost analyses encompassed overall and PICU admissions, consultations with allied health care professionals, medical services, pharmaceutical services, and NTBC prescriptions. For hospital admissions, descriptive analyses included number of general and PICU admissions and length of stay. A sub-analysis was conducted for costs associated with liver transplant alone.

Cost analyses factored in the effects of mortality. To reflect differences among patients in the duration of follow-up, all results were expressed in person-years, representing the actual time that each patient contributed to the study. For pharmaceutical services, the cost analysis was performed only from 1997, the start date of the RAMQ pharmaceutical database, and included all patients who were covered by the RAMQ drug plan for at least 1 month.

Because the data were not normally distributed, the nonparametric Kruskal-Wallis test was used for 3-group comparisons and the Wilcoxon Mann-Whitney test for 2-group analyses. The bootstrap method was applied to cost comparisons. Data analyses were performed with SAS statistical software, release 9.2 (SAS Institute Inc., Cary, North Carolina). All statistical analyses were conducted by a biostatistician (M.D.).

\section{RESULTS}

A total of 95 patients were treated for HT1 between 1984 and 2008: 28 in the no-NTBC group, 26 in the late-intervention group, and 41 in the early-intervention group. No patients were lost to follow-up. Of 503 hospital admissions, 12 (2.4\%) were 
excluded for causes not attributable to HT1 (fractures, strabismus, dental problems). The mean duration of follow-up was 12.6 years, 13.6 years, and 6.2 years for the no-NTBC, late-intervention, and early-intervention groups, respectively.

The median age at the study end date differed markedly among groups: 18.2 years, 13.6 years, and 7.4 years in the no-NTBC, late-intervention, and early-intervention groups, respectively $(p<0.001)$ (Table 1$)$. In the no-NTBC group $(n=$ 28 patients), all of those who did not receive a liver transplant died (8/8 [100\%]); in contrast, of the 20 patients who did receive a transplant, only $2(10 \%)$ died. The incidence of porphyria-like neurologic crises differed between groups: 51 crises affected 14 patients in the no-NTBC group, and 16 crises affected 5 patients in the late-intervention group (all occurring before NTBC initiation), whereas no crises occurred in the early-intervention group.

\section{NTBC Therapy}

NTBC therapy was initiated at a median of 1 year after birth in the late-intervention group, as compared to 13 days after birth in the early-intervention group. The total number of patients treated increased from 23 in 1997 to 61 in 2008 . The 2 patients in the late-intervention group who required a liver transplant after 1997 stopped their NTBC. The annual per-patient cost of NTBC therapy rose from \$35 611 in 1997 to \$68920 in 2007. This increase may be attributable to an increase in the unit price of the medication, combined with increases in dose (based on the increasing weight of the growing children). The costs of NTBC per person-year were $\$ 64895$ for the late-intervention group and \$51 493 for the early-intervention group, reflecting the younger age of the children in the more recent historical group (Table 2).

\section{Hospital Admissions}

NTBC therapy was associated with a significant reduction in hospital admissions, in terms of both number of admissions per person-year $(0.83,0.41$, and 0.16 for the no-NTBC, lateintervention, and early-intervention groups, respectively; $p<0.001$ ) and length of stay (Table 2). As a result, the administration of NTBC was associated with a marked decrease in hospital costs, particularly with early intervention. Overall hospital costs per person-year were $\$ 12$ 980, \$5 590, and \$673 for the no-NTBC, late-intervention, and early-intervention groups, respectively $(p<0.001)$.

Table 1. Patient Characteristics

\begin{tabular}{|c|c|c|c|c|}
\hline \multirow[b]{2}{*}{ Characteristic } & \multicolumn{3}{|c|}{ Group; No. (\%) of Patients* } & \multirow[b]{2}{*}{$p$ Value } \\
\hline & $\begin{array}{l}\text { No-NTBC Group } \\
\quad(n=28)\end{array}$ & $\begin{array}{l}\text { Late-Intervention } \\
\text { Group }(n=26)\end{array}$ & $\begin{array}{l}\text { Early-Intervention } \\
\text { Group }(n=41)\end{array}$ & \\
\hline Sex & & & & $0.52 \dagger$ \\
\hline Girls & $14 \quad(50)$ & $9 \quad(35)$ & $17 \quad(41)$ & \\
\hline Boys & $14 \quad(50)$ & $17 \quad(65)$ & $24 \quad(59)$ & \\
\hline $\begin{array}{l}\text { No. of patients alive at } \\
\text { January } 1,2009\end{array}$ & 18 & 24 & 41 & \\
\hline \multicolumn{5}{|l|}{ 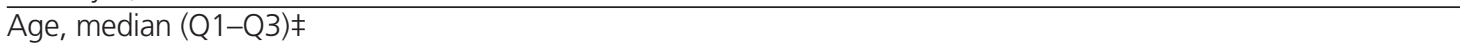 } \\
\hline $\begin{array}{l}\text { At January 1, } 2009 \\
\text { (study end date) }\end{array}$ & $\begin{array}{c}18.2 \mathrm{yr} \\
(16.3-21.7)\end{array}$ & $\begin{array}{c}13.6 \mathrm{yr} \\
(12.6-15.0)\end{array}$ & $\begin{array}{c}7.4 \mathrm{yr} \\
(3.4-8.5)\end{array}$ & $<0.001 \S$ \\
\hline At first NTBC administration & NA & $\begin{array}{c}1.0 \mathrm{yr} \\
(0.4-2.2)\end{array}$ & $\begin{array}{c}13 d \\
(11-16)\end{array}$ & \\
\hline \multicolumn{5}{|l|}{ Neurologic crises } \\
\hline No. (\%) of patients with crisis & $14(50)$ & $5(19)$ & 0 & $<0.001 * *$ \\
\hline Total no. of crises & 51 & 16 & 0 & \\
\hline Crises per patient, median (Q1-Q3) & $3(1-6)$ & $1(1-4)$ & & \\
\hline \multicolumn{5}{|l|}{ Liver transplants } \\
\hline No. (\%) of patients with transplant & $20(71)$ & $7(27)$ & 0 & $<0.001 * *$ \\
\hline $\begin{array}{l}\text { Age at transplant (yr), median } \\
\text { (Q1-Q3) }\end{array}$ & $\begin{array}{c}2.0 \\
(1.0-2.8)\end{array}$ & $\begin{array}{c}4.8 \\
(2.9-7.6)\end{array}$ & NA & \\
\hline \multicolumn{5}{|l|}{ Deaths } \\
\hline No. (\%) of patients & $10(36)$ & $2(8)$ & 0 & $<0.001 * *$ \\
\hline $\begin{array}{l}\text { Age at death (yr), median } \\
\text { (Q1-Q3) }\end{array}$ & $\begin{array}{c}1.1 \\
(0.6-2.1)\end{array}$ & $\begin{array}{c}8.1 \\
(7.4-8.7)\end{array}$ & NA & \\
\hline
\end{tabular}

NA = not applicable, NTBC = nitisinone, Q1 = first quartile, Q3 = third quartile.

*Except where indicated otherwise.

$+x^{2}$ test.

\#Excluding those who died.

§Kruskal-Wallis test.

ๆln the late-intervention group, all crises occurred before initiation of NTBC.

**Fisher exact test. 
This single copy is for your personal, non-commercial use only.

For permission to reprint multiple copies or to order presentation-ready copies for distribution, contact CJHP at cjhpedit@cshp.ca

Table 2. Health Care Resource Utilization and Associated Costs

\begin{tabular}{|c|c|c|c|c|}
\hline Resource & $\begin{array}{c}\text { No-NTBC Group } \\
(n=21)^{*}\end{array}$ & $\begin{array}{l}\text { Late-Intervention } \\
\text { Group }(n=26)\end{array}$ & $\begin{array}{l}\text { Early-Intervention } \\
\text { Group }(n=41)\end{array}$ & $p$ Valuet \\
\hline Hospitalization‡ & & & & NT \\
\hline No. of admissions, including PICU & 273 & 178 & 40 & \\
\hline No. of days in hospital & 2489 & 1377 & 105 & \\
\hline No. of admissions, PICU only & 17 & 15 & 1 & \\
\hline No. of days, PICU only & 177 & 211 & 7 & \\
\hline \multicolumn{5}{|l|}{ Events per person-year } \\
\hline Admissions, including PICU & 0.83 & 0.41 & 0.16 & $<0.001$ \\
\hline Days in hospital & 7.6 & 3.2 & 0.4 & $<0.001$ \\
\hline Admissions, PICU only & 0.05 & 0.04 & 0.004 & $<0.001$ \\
\hline Days, PICU only & 0.5 & 0.5 & 0.03 & $<0.001$ \\
\hline Allied professional consultations§ & 1.28 & 0.65 & 0.08 & $<0.001$ \\
\hline \multicolumn{5}{|l|}{ Cumulative costs $\uparrow, \$$} \\
\hline Hospital admissions, including PICU & 4371480 & 2304329 & 170170 & \\
\hline Hospital admissions, PICU only & 576267 & 348886 & 19199 & \\
\hline Allied professional consultations§ & 31512 & 20596 & 1030 & \\
\hline Medical services & 1079967 & 701140 & 192869 & \\
\hline $\begin{array}{l}\text { Pharmaceutical services, } \\
\text { excluding NTBC***}\end{array}$ & 301410 & 147437 & 11996 & \\
\hline NTBC only & - & 16496387 & 13007067 & \\
\hline \multicolumn{5}{|l|}{ Costs per person-yearף, \$ } \\
\hline Hospital admissions, including PICU & 12980 & 5590 & 673 & $<0.001$ \\
\hline Hospital admissions, PICU only & 1768 & 846 & 76 & $<0.001$ \\
\hline Allied professional consultations§ & 96 & 50 & 4 & $<0.001$ \\
\hline Medical services & 3028 & 1632 & 763 & $<0.001$ \\
\hline $\begin{array}{l}\text { Pharmaceutical services, } \\
\text { excluding NTBC*** }\end{array}$ & 3674 & 1144 & 144 & $<0.001$ \\
\hline NTBC only & - & 64895 & 51493 & $<0.001$ \\
\hline
\end{tabular}

NTBC = nitisinone, PICU = pediatric intensive care unit, NT = not tested (values not reported per person-year).

*The original no-NTBC group had 28 patients, but 7 patients died within their first year, and no data are available for them.

†Kruskal-Wallis test for events per person-year, bootstrap test for costs per person-year.

fIn the 2 groups treated with NTBC, at least one hospital admission was attributable to diagnosis and treatment initiation. Hospital admissions occurring after treatment (liver transplant) were included and are essentially related to post-transplant surveillance and complications.

$\S$ Allied professional consultations: those performed by health care professionals, other than physicians, during hospital stays and outpatient visits.

ๆCosts reported in 2008 Canadian dollars. Stay on the ward was estimated at \$528/day in 1987 and \$1 925/day in 2008. Stay in PICU was estimated at \$915/day in 1987 and \$3 337/day in 2008.

**Pharmaceutical services include pharmacist fees and were available only for patients covered by the drug plan of the Régie de l'Assurance maladie du Québec: no-NTBC group $(n=10)$, late-intervention group $(n=9)$, and early-intervention group ( $n=19)$; data were available starting in 1997.

\section{Medical and Pharmaceutical Services}

The costs of medical services per person-year were significantly lower for patients in the early-intervention group, relative to the late-intervention and no-NTBC groups (Table 2). An equally pronounced effect was observed for pharmaceutical services, excluding the costs of NTBC.

\section{Liver Transplants}

The length of stay in hospital for liver transplant was significantly lower in the late-intervention group (median 23 days; 1.8 days per person-year) than in the no-NTBC group (median 38.5 days; 2.7 days per person-year; $p=0.03$ ) (Table 3). The 20 transplants in the no-NTBC group dated from 1988 to 1996 , and the 7 transplants in the late-intervention group, from 1994 to 2007. Hospital admissions and associated medical services per person-year were significantly less costly for the late-intervention group.

\section{DISCUSSION}

It is crucial to assess the ability of therapeutic agents to improve survival and quality of life for patients with rare metabolic diseases. However, the small number of families and individuals affected by rare diseases means that the per-patient cost of therapeutic innovation is often prohibitively expensive, and standard development of therapies on the basis of clinical trial-based evidence is not readily feasible. 
This single copy is for your personal, non-commercial use only.

For permission to reprint multiple copies or to order presentation-ready copies for distribution, contact CJHP at cjhpedit@cshp.ca

Table 3. Costs of Liver Transplants and Directly Associated Medical Expenses*

\begin{tabular}{|c|c|c|c|}
\hline Variable & $\begin{array}{l}\text { No-NTBC Group } \\
\quad(n=20)\end{array}$ & $\begin{array}{l}\text { Late-Intervention } \\
\text { Group }(n=7)\end{array}$ & $p$ Valuet \\
\hline Timeframe & 1988-1996 & 1994-2007 & NT \\
\hline \multicolumn{4}{|l|}{ Events } \\
\hline $\begin{array}{l}\text { No. of hospital admissions } \\
\text { for transplant }\end{array}$ & 20 & 7 & NT \\
\hline $\begin{array}{l}\text { No. of days in hospital, } \\
\text { per person-year }\end{array}$ & 2.7 & 1.8 & 0.03 \\
\hline \multicolumn{3}{|l|}{ Cumulative costs, $\$$} & NT \\
\hline Hospital admissions & 1547925 & 335170 & \\
\hline Hospital drugs $\neq$ & 74289 & 25696 & \\
\hline Blood-derived products§ & 150098 & 94202 & \\
\hline Medical services $\mathbb{1}$ & 517314 & 163102 & \\
\hline \multicolumn{3}{|l|}{ Cost per transplant, median (Q1-Q3), \$ } & NT \\
\hline Hospital drugs $\neq$ & $\begin{array}{c}3675 \\
(3401-3732)\end{array}$ & $\begin{array}{c}3424 \\
(3186-3693)\end{array}$ & \\
\hline Blood-derived products§ & $\begin{array}{c}7810 \\
(3177-9380)\end{array}$ & $\begin{array}{c}6774 \\
(639-14341)\end{array}$ & \\
\hline \multicolumn{4}{|l|}{ Cost per person-year, $\$$} \\
\hline Hospital admissions & 5044 & 3198 & $<0.001$ \\
\hline Medical services & 1677 & 1553 & $<0.001$ \\
\hline \multicolumn{4}{|c|}{$\begin{array}{l}\text { NTBC = nitisinone, Q1 = first quartile, Q3 = third quartile, NT = not tested. } \\
{ }^{*} \text { Costs are reported in } 2008 \text { Canadian dollars. Stay on the ward was estimated at } \$ 528 / \text { day } \\
\text { in } 1987 \text { and } \$ 1925 / \text { day in } 2008 \text {. Stay in the pediatric intensive care unit was estimated at } \\
\$ 915 / \text { day in } 1987 \text { and } \$ 3337 / \text { day in } 2008 \text {. } \\
\text { tWilcoxon Mann-Whitney test for events, bootstrap test for costs per person-year. } \\
\text { fData available from records of the hospital pharmacy of Centre hospitalier universitaire } \\
\text { (CHU) Sainte-Justine. } \\
\text { \$Data available from blood bank database and hospital records of CHU Sainte-Justine. } \\
\text { ๆFor medical services, } n=19 \text { for the no-NTBC group (data missing for one patient). Medical } \\
\text { services included costs related to medical visits, surgeries, medical procedures, and related } \\
\text { treatments. }\end{array}$} \\
\hline
\end{tabular}

For children with HT1, liver transplant was a life-saving procedure. Although renal tubular dysfunction remained, transplant was deemed a cure for the disease. ${ }^{24}$ However, the procedure itself carried certain risks. Associated mortality was $10 \%-15 \%$, and non-negligible complications included side effects, the need for lifelong immunosuppressive therapy and follow-up, and diminished quality of life, all associated with direct and indirect costs.

The advent of NTBC dramatically changed the prognosis and quality of life for patients with HT1. When administered starting within 4 weeks after birth, NTBC prevented neurologic crises and HT1-associated deaths and obviated the need for liver transplant in this cohort. Indeed, in the current study, fewer hospital admissions, PICU admissions, and allied health care consultations were observed in the NTBC intervention groups, particularly when the drug was initiated early. There was a significant reduction in HT1-associated costs, including those for hospital admissions, liver transplant, medical visits, and pharmaceutical services (other than NTBC). For the earlyintervention group, the costs per person-year were minor. Some of the important factors contributing to cost were liver transplant and PICU admissions.
Because of its relatively recent introduction, the long-term effects of NTBC, as well as the late effects of the underlying tyrosinemia, remain largely unknown. In a retrospective study of 46 patients in France treated after 1992 for an average of 4.75 years (31 patients with initiation of therapy before 6 months of age, 10 with initiation between 6 and 24 months of age, and 5 with initiation after 24 months of age), the timing of NTBC intervention was found to have a major effect on the therapeutic response. ${ }^{25}$ Of 4 patients who required liver transplant, 3 had late initiation of NTBC (after 24 months of age); in addition, the 2 cases of hepatocellular carcinoma originated in patients whose NTBC therapy was initiated after 24 months. One death occurred, related to liver transplant, for a 98\% HT1 survival rate. Although no neurologic crises were documented, corneal inflammation and transitory anomalies in blood laboratory values were noted in some patients, as well as cognitive impairment leading to learning difficulties and elevated $\alpha$-fetoprotein, which implied continued cancer risk. ${ }^{25}$

A multisite uncontrolled study of 207 patients in 25 countries (performed between 1991 and 1997) investigated NTBC combined with a low-tyrosine, low-phenylalanine diet and showed 2- and 4-year survival rates of 96\% ( $n=95$ patients) and 
93\% ( $n=35$ patients), respectively. When the only available treatment was diet modification, 4-year survival among patients in whom symptoms developed before 2 months of age was $29 \%$. The authors reported reductions in liver transplants and the incidence of liver cancer, as well as almost complete elimination of neurologic crises. ${ }^{26}$

The NTBC safety profile seems favourable. ${ }^{11,26}$ Nonetheless, long-term studies are needed to elucidate the cognitive effects of prolonged treatment of $\mathrm{HT} 1$ with $\mathrm{NTBC}$ and to further evaluate the underlying risk of liver cancer in HT1. ${ }^{25}$

This study had some inherent limitations. First, the symptoms were variable and the prevalence of HT1 was low. For a rare disease, the sample size was substantial (95 patients), yet the statistically small and widely variable sample limited the ability to perform clinical and demographic subgroup analyses. Second, the study periods for the 3 groups extended over 25 years, which incurred secular trend historical bias because of changes in health care practices (e.g., lower complication rates, improvements in postoperative management), reductions in hospital lengths of stay, and changes in costs (e.g., increased medical, professional, and pharmaceutical fees). Third, it was not possible to access data for the 7 patients in the no-NTBC group who died in the first year of life; however, the effect of these missing data on longterm costs should be rather low, given the short follow-up period for these individuals. Fourth, the use of per diem costs to evaluate hospital costs may have underestimated actual figures. Other data, however, served as correction factors to allow more accurate representation of HT1-related expenses. The RAMQ medical services database provided supplementary information such as physician fees and costs for associated medical acts not included in the hospital per diem. Costs of transplant-specific medications and blood products were obtained directly from hospital sources. However, the data on community prescriptions were incomplete, as the RAMQ database did not include patients with private insurance, nor did it include data preceding 1997 (when the government drug insurance program was started).

This study also had a number of major strengths. First, the study team was based in a tertiary referral centre for all Quebec patients with HT1. Furthermore, the province of Quebec has the highest incidence of this disease worldwide, which allowed access to the largest possible number of cases. Second, the quality of follow-up by the Québec NTBC Study Group was remarkable: not one patient was lost to follow-up over the 25-year period. Third, the quality of clinical data and its relevance were high; each patient was evaluated by a team of specialists closely involved in studying HT1 over the targeted time frames. Finally, because the CHU Sainte-Justine was the referral centre for a large geopolitical area, all sociodemographic levels were represented, as were a diversity of clinical and genetic presentations.

\section{CONCLUSIONS}

The cost of NTBC was substantial. However, without this drug, these pediatric patients would not have survived past the first years of life unless they received a liver transplant. Deaths were eliminated, liver transplants were almost eliminated, and morbidity was reduced, particularly when NTBC was initiated in the first weeks after birth, thus preventing early damage to the liver and kidneys. The costs of all forms of health care resource utilization were dramatically reduced. Furthermore, this study has demonstrated the utility of this type of analysis in determining whether a new therapy for a rare disease is beneficial to the individual and to society.

References

1. Paradis K. Tyrosinemia: the Quebec experience. Clin Invest Med. 1996;19(5):311-6.

2. Mitchell GA, Lambert M, Tanguay RM. Hypertyrosinemia. In: Scriver CR, Beaudet AL, Sly WS, Valle D, editors. The metabolic and molecular bases of inherited disease. 7th ed. New York (NY): McGraw Hill; 1995. p. 1077-106.

3. Laflamme N, Fortier M, Lindsay C, Turgeon J. Rapport d'évaluation du programme de dépistage sanguin des maladies génétiques chez le nouveau-né. Québec (QC): Institut national de santé publique du Québec; 2005. $251 \mathrm{p}$.

4. Renaud J, Dagenais P. La pertinence du dépistage néonatal urinaire des erreurs innées du métabolisme réalisé au Québec. Montréal (QC): Agence d'évaluation des technologies et des modes d'intervention en santé; 2009.

5. Tyrosinémie héréditaire de type I. In: Orphanet, serveur d'information sur les maladies rares et les médicaments orphelins [website]. Paris (France): INSERM; [cited 2009 May 7]. Available from : www.orpha.net/consor/cgibin/ OC_Exp.php?lng= EN\&Expert $=882$

6. Drugdex evaluation: nitisinone [electronic database]. Micromedex Healthcare Series; (C) 1974-2009.

7. van Spronsen FJ, Thomasse Y, Smit GP, Leonard JV, Clayton PT, Fidler V et al. Hereditary tyrosinemia type I: a new clinical classification with difference in prognosis on dietary treatment. Hepatology. 1994;20(5):1187-91.

8. Holme E, Lindstedt S. Nontransplant treatment of tyrosinemia. Clin Liver Dis. 2000;4(4):805-14.

9. Larochelle J, Alvarez F, Bussières JF, Chevalier I, Dallaire L, Dubois J et al. Effect of nitisinone (NTBC) treatment on the clinical course of hepatorenal tyrosinemia in Québec. Mol Genet Metab. 2012;107(1-2):49-54.

10. Grompe M. The pathophysiology and treatment of hereditary tyrosinemia type 1. Semin Liver Dis. 2001;21(4):563-71.

11. Orfadin $®$, nitisinone [product information]. Nashville (TN): Rare Disease Therapeutics Inc; 2004.

12. Drummond MF, O'Brien B, Stoddart GL, Torrance GW. Methods for the economic evaluation of health care programmes. 2nd ed. Oxford (UK): Oxford University Press; 1997. p. 11-7, 74-111.

13. Régie de l'assurance maladie du Québec [website]. Québec (QC): Régie de l'assurance maladie du Québec; [cited 2015 June 4]. Available from: www.ramq.gouv.qc.ca/fr/Pages/accueil.aspx

14. Manual of the International Statistical Classification of Diseases and Related Health Problems. 9th revision. Geneva (Switzerland): World Health Organization; 1977.

15. Manual of the International Statistical Classification of Diseases and Related Health Problems. 10th revision. Geneva (Switzerland): World Health Organization; 2004.

16. Canadian classification of diagnostic, therapeutic, and surgical procedures. 2nd ed. Ottawa (ON): Statistics Canada, Health Division; 1986.

17. Tamblyn R, Lavoie G, Petrella L, Monette J. The use of prescription claims databases in pharmacoepidemiological research: the accuracy and comprehensiveness of the prescription claims database in Quebec. J Clin Epidemiol. 1995;48(8):999-1009.

18. Wilchesky M, Tamblyn RM, Huang A. Validation of diagnostic codes within medical services claims. J Clin Epidemiol. 2004;57(2):131-41.

19. Manuels des médecins spécialistes RAMQ. Québec (QC): Régie de l'assurance maladie du Québec; [cited 2009 May 7]. Available from: www. ramq.gouv.qc.ca/fr/professionnels/medspe/manuel/manu_tdm.shtml 
20. Manuels des médecins omnipraticiens RAMQ. Québec (QC): Régie de l'assurance maladie du Québec; [cited 2009 May 7]. Available from: www.ramq.gouv.qc.ca/fr/professionnels/medomni/manuel/manu_tdm.shtml

21. Association québécoise d'établissements de santé et de services sociaux [website]. Montréal (QC) : The Association; [cited 2009 May 7]. Available from: www.aqesss.qc.ca/fr/accueil.aspx

22. Exchange rates. Ottawa (ON): Bank of Canada; [cited 2012 Jan 4]. Available from: www.bankofcanada.ca/rates/exchange

23. Guidelines for the economic evaluation of health technologies: Canada. 3rd ed. Ottawa (ON): Canadian Agency for Drugs and Technologies in Health; 2006.

24. Pierik LJ, van Spronsen FJ, Bijleveld CM, van Dael CM. Renal function in tyrosinaemia type I after liver transplantation: a long-term follow-up. $J$ Inherit Metab Dis. 2005;28(6):871-6.

25. Masurel-Paulet A, Poggi-Bach J, Rolland MO, Bernard O, Guffon N, Dobbelaere D, et al. NTBC treatment in tyrosinaemia type I: long-term outcome in French patients. J Inherit Metab Dis. 2008;31(1):81-8.

26. Orfadin (nitisinone) : rapport européen public d'évaluation. London (UK): European Medicines Agency; 2005 [cited 2009 May 7]. Available from: www.emea.europa.eu/humandocs/PDFs/EPAR/Orfadin/3202905 en6.pdf

Mariève Simoncelli, BPharm, MSc, is with the Health Technology Assessment Unit, Centre hospitalier universitaire Sainte-Justine, Montréal, Quebec.

Johanne Samson, MSc, is with the Health Technology Assessment Unit, Centre hospitalier universitaire Sainte-Justine, Montréal, Quebec.

Jean-François Bussières, BPharm, MSc, MBA, FCSHP, is with the Pharmacy Practice Research Unit and the Pharmacy Department, Centre hospitalier universitaire Sainte-Justine, and the Faculty of Pharmacy, Université de Montréal, Montréal, Quebec.

Jacques Lacroix, MD, FRCPC, FAAP, is with the Department of Pediatrics, Université de Montréal and the Centre hospitalier universitaire SainteJustine, Montréal, Quebec.
Marc Dorais, MSc, is with StatSciences Inc, Notre-Dame-de-l'Île-Perrot, Quebec.

Renaldo Battista, MD, MPH, SCD, FRCPC, is with the Fonds de recherche du Québec-Santé, Montréal, Quebec

Sylvie Perreault, BPharm, PhD, is with the Faculty of Pharmacy, Université de Montréal, Montréal, Quebec.

Competing interests: None declared.

Address correspondence to:

Dr Sylvie Perreault

Faculty of Pharmacy

Université de Montréal

PO Box 6128, Succursale Centre-Ville

Montréal QC H3C 3J7

e-mail: sylvie.perreault@umontreal.ca

Acknowledgements: The authors would like to thank Alicia Framarin, Scientific Director, Institut national d'excellence en santé et en services sociaux (methodological and scientific support); Carole St-Hilaire, Associate Director for Performance, McGill University Health Centre (assistance with cost analyses and discounting); and the Centre hospitalier universitaire (CHU) Sainte-Justine and Unité d'évaluation des technologies et des modes d'intervention en santé (UETMIS). The authors would also like to thank the physicians of the Québec NTBC Study Group, who were responsible for patient care during the period of this study, including the physicians who coordinated patient care: Jean Larochelle and Guy Parizeault of Hôpital de Chicoutimi, Rachel Laframboise and Bruno Maranda of the Centre hospitalier de I'Université Laval, John Mitchell of the Centre universitaire de santé McGill, and Grant Mitchell of the CHU Sainte-Justine. Grant Mitchell also participated in discussions during the course of this project and commented on the manuscript. The authors are grateful to Danielle Buch, medical writer/editor at the Applied Clinical Research Unit of the CHU Sainte-Justine Research Centre, for translation of the manuscript and editing.

Funding: Sylvie Perreault holds the Sanofi Aventis Endowment Chair in Drug Utilization at the Université de Montréal. This work was supported by a grant from the Clinical Research and Health Technology Assessment Program at CHU Sainte-Justine. The funding source had no role in the study's design, conduct, or reporting.

\section{CJHP Call for Cover Photos: Canadian Landscapes \& Scenery}

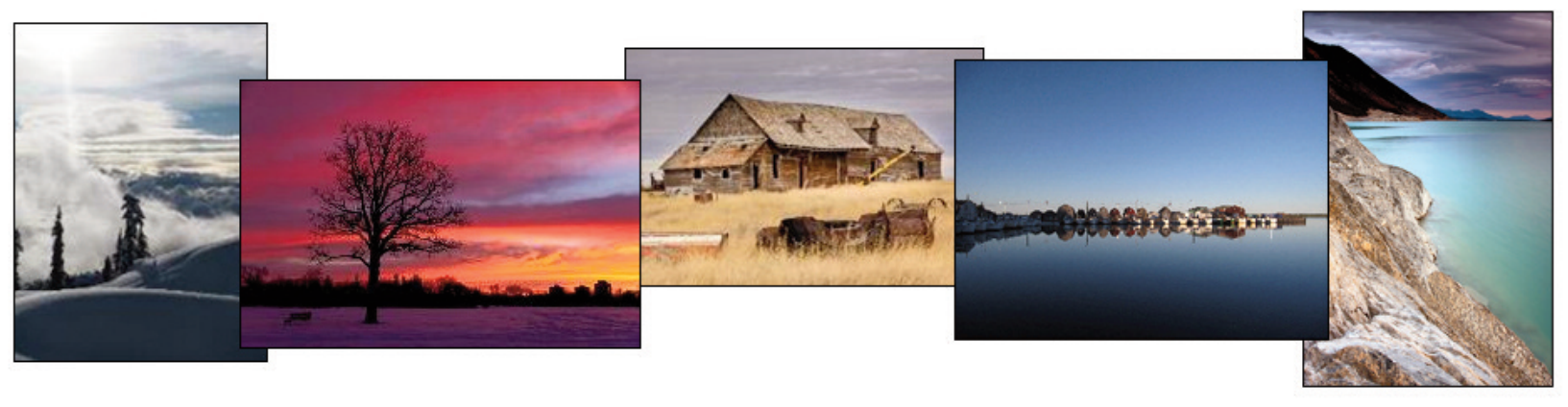

Send your digital photograph (or selection of photographs), along with a short write-up (max. 150 words) about when and where the photo was taken, and the type of equipment used, to the CSHP Publications Administrator at cjhpedit@cshp.ca 